\title{
Preparation of Agave tequilana Weber Nanocrystalline Cellulose and its Use as Reinforcement for Acrylic Hydrogels
}

\author{
Rosa María Jiménez-Amezcua, ${ }^{a}$ Robert Josep Villanueva-Silva, ${ }^{\mathrm{b}}$ Rubén Octavio Muñoz- \\ García, ${ }^{\mathrm{c}}$ Emma Rebeca Macias-Balleza, ${ }^{\mathrm{a}}$ María Thais Helena Sydenstricker Flores- \\ Sahagún, ${ }^{\mathrm{d}}$ María Guadalupe Lomelí-Ramírez, ${ }^{\mathrm{e}}$ José Guillermo Torres-Rendón, ${ }^{\mathrm{e}}$ and \\ Salvador García-Enriquez ${ }^{\mathrm{e}, *}$
}

\begin{abstract}
Nanocrystalline cellulose (NCC) was prepared from Agave tequilana Weber blue variety via acid hydrolysis. The NCC was used in forming acrylic acid/acrylamide hydrogels (AA/AM), $(80 / 20 \mathrm{w} / \mathrm{w})$, crosslinked with $\mathrm{N}-\mathrm{N}$-methylene bisacrylamide (MBA) at addition levels of $1,2,4$, and 8 $w t \%$ of the monomeric phase. The NCC was dosed at $0.1,0.5$, and 1.0 $w t \%$. Two synthesis routes were used. In the first route, polymerization was performed immediately after mixing the components. In the second route, the mixture of the components was kept at $2{ }^{\circ} \mathrm{C} \pm 1{ }^{\circ} \mathrm{C}$ for $24 \mathrm{~h}$ before the polymerization (thermal treatment). All the hydrogels were characterized by nuclear magnetic resonance (NMR), water absorption tests, scanning electron microscope (SEM) analysis, and rheology tests. The NCC particles had a diameter of approximately $75 \mathrm{~nm}$. The hydrogels that were subjected to the thermal treatment reached the equilibrium after approximately $72 \mathrm{~h}$. The un-treated hydrogels reached the equilibrium after approximately $58 \mathrm{~h}$. The thermally treated samples had a lower swelling degree and the swelling degree decreased as the crosslinking degree and the NCC concentration increased. The swelling kinetics followed the Schott's pseudo-second-order.
\end{abstract}

Keywords: Agave tequilana Weber var. azul; Hydrogels; Cellulose nanocrystals; NCC

Contact information: a: Department of Chemical Engineering, University Center for Exact Sciences and Engineering, University of Guadalajara, Blvd. Marcelino García Barragán \#1421, Guadalajara, Mexico; b: Department of Chemical Engineering, Technological Institute of Ciudad Madero, First de Mayo street, Postal Code 89440, Madero City, Mexico; c: Department of Chemistry, University Center for Exact Sciences and Engineering, University of Guadalajara, Blvd. Marcelino García Barragán \#1421, Guadalajara, Mexico; d: Department of Mechanical Engineering, Federal University of Paraná, Coronel Francisco H. dos Santos Avenue 100, Jardim das Américas, Curitiba - PR, 81530-000, Brazil; e: Department of Wood, Cellulose and Paper, University Center for Exact Sciences and Engineering, University of Guadalajara, km 15.5 at the Guadalajara-Nogales Highway, Postal Code 45220, Zapopan, Mexico;

*Corresponding author: salvador.genriquez@academicos.udg.mx

\section{INTRODUCTION}

Nanocrystalline cellulose (NCC), which is also called cellulose nanocrystals, is a biodegradable and biocompatible material that presents high crystallinity, high specific surface area, a high Young modulus, and a low density. These remarkable mechanical and surface chemistry properties give NCC the potential to be used as a structural reinforcement material (Lam et al. 2012; Morelli et al. 2012; Rosli et al. 2013; Yang et al. 2013). NCC 
is composed of individual cellulose nanocrystals. According to Rosli et al. (2013) and Lam et al. (2012), cellulose nanocrystals are elongated rod-like cellulose nanoparticles that present a rigid rod-shape structure, 5 to $70 \mathrm{~nm}$ in diameter and tens to hundreds of nanometers in length. Individual cellulose nanocrystals have a tensile strength of approximately $7500 \mathrm{MPa}$, a Young's modulus between $100 \mathrm{GPa}$ and $140 \mathrm{GPa}$, an aspect ratio of approximately 70 , and a surface area between $150 \mathrm{~m}^{2} / \mathrm{g}$ and $250 \mathrm{~m}^{2} / \mathrm{g}$.

The typical processes to isolate NCC include mechanical, chemical, or enzymatic treatments (Masruchin et al. 2015). The main chemical process to obtain NCC is through hydrolysis with the use of strong acids, where the amorphous regions of the cellulose fibers are attacked, and the amorphous phase is removed (Habibi et al. 2010; Yang et al. 2012).

The size and morphology of the NCC is strongly related to the process used to obtain the cellulose (Brinchi et al. 2013) and to the source of the cellulose. For example, coconut husk (Rosa et al. 2010), kenaf (Kargarzadeh et al. 2012), banana pseudostems (Pereira et al. 2014), corn stalk residues (Motaung and Mtibe 2015), or firewood materials such as balsa wood (Lipparelli et al. 2012) and pine (Zhang et al. 2014) can be used to manufacture NCC.

The production of agave in Mexico, especially in the state of Jalisco, is a very important industrial activity because of the tequila production. In 2019, 1,342,600 tons of agave were consumed, which produced 387,000 tons of agave bagasse (Tequila Regulatory Council, Mexico 2020), a fibrous by-product obtained in the industrial production of tequila. Unfortunately, the high quantity of bagasse waste creates negative environmental challenges in terms of management and removal of agricultural waste (Huitrón et al. 2008). In the last decade, great efforts to exploit the A. tequilana bagasse have been made. Several studies indicate that cellulose content of $A$. tequilana bagasse is around $80 \%$ (Ponce Reyes et at. 2014; Gallardo-Sánchez et al. 2019). For this reason, this type of bagasse can be considered a prime candidate to be used as a starting material for the preparation of high value-added subproducts, such as cellulose nanocrystals (Pech-Cohuo et al. 2018; Gallardo-Sánchez et al. 2021).

Due to its lignocellulosic nature, strong mechanical properties, abundant availability from renewable sources, and its application in materials such as polymeric nanocomposites, NCC has gained a lot of attention in recent years (Peng et al. 2011; Pereira et al. 2014). Preparation of nanocelluloses from lignocellulosic biomass opens new opportunities for the development of new materials with potential applications in several fields. For example, nanocellulose-based hydrogels have emerged as promising materials in the field of biomedicine in the last decade. This is due to their low toxicity, biocompatibility, and remarkable mechanical stability (Du et al. 2019).

However, hydrogels often show poor mechanical properties because of the random nature of the crosslinking reactions in the polymers and the high absorption of water, which limits its use in structural applications (Sanna et al. 2013). Hydrogels are three-dimensional nets of polymer that contain hydrophilic groups and have interesting properties such as a hydrophilic character, flexibility, and smoothness in touch and elasticity. Hydrogels absorb water, which enhances the volume of the hydrogel considerably while maintaining its shape, until a physicochemical equilibrium is reached.

Hydrogels are sensitive to different stimuli such as light, ionic force, temperature, $\mathrm{pH}$, electric campus, or solvent concentration. The hydrophilic nature of hydrogels favors the capture of water in the net when they are immersed in aqueous and polar environments. Hydrogels may be used in separation processes in biotechnology, as superabsorbent materials, pharmaceutical administration, and in areas where biomaterials are used. 
Hydrogels may be synthesized by different initiation methods such as thermal, redox, and photopolymerization (Lopez-Ureta et al. 2008; Gómez et al. 2012). The photopolymerization technique is fast, it may be carried out at room temperature, and it does not require organic solvents (Klemm et al. 2018). The photopolymerization technique also offers advantages such as dimensional control and the possibility of easily adding reinforcement agents (Vermonden et al. 2012). One of the advantages of forming nanocomposite hydrogels is the good dispersion of the reinforcement agent in the polymeric matrix, which enhances the interfacial interactions between the matrix and the reinforcing materials. The introduction of a nanometric material as a stuffing material in a hydrogel structure may result in dimensional stability and improvement in the mechanical properties of the swallowed hydrogels in aqueous or polar environments. The main aim of this work was to obtain and characterize NCC from Agave tequilana bagasse and use it to prepare and characterize reinforced acrylic hydrogels.

\section{EXPERIMENTAL}

\section{Materials}

The A. tequilana Weber blue variety was obtained as bagasse residue from a tequila facility in Jalisco, Mexico. Sulfuric acid $\left(\mathrm{H}_{2} \mathrm{SO}_{4}\right)$ (96 to $98 \%$ ), sodium hydroxide ( $\left.\mathrm{NaOH}\right)$ (97\%), and chlorine dioxide $\left(\mathrm{ClO}_{2}\right)(98 \%)$ were acquired from Golden Bell Reactivos (Guadalajara, Mexico). Antraquinone (AQ) (97\%), acrylamide (AM) (98.5\%), acrylic acid (AA) (99.3\%), 2-2-dimethoxy-2-phenylacetophenone (DPA) (99\%), and N-N-methylene bisacrylamide (MBA) (99\%) were purchased from Sigma-Aldrich (Toluca, Mexico). The methanol (96\%) was obtained from J.T. Baker (Monterrey, Mexico).

\section{NCC Preparation}

The agave bagasse was subjected to an acid hydrolysis treatment with a $0.5 \mathrm{wt} \%$ $\mathrm{H}_{2} \mathrm{SO}_{4}$ solution. The agave bagasse and the $\mathrm{H}_{2} \mathrm{SO}_{4}$ were placed in a rotary pulp digester (Scientific and Technical Services at the UPC, Barcelona, Spain) at an 8:1 liquid-to-solid ratio for $30 \mathrm{~min}$ at $160{ }^{\circ} \mathrm{C}$. Then, the bagasse was cooked for $150 \mathrm{~min}$ in a rotary reactor (Scientific and Technical Services at the UPC, Barcelona, Spain) at $170{ }^{\circ} \mathrm{C}$ with an $18 \mathrm{wt} \%$ $\mathrm{NaOH}$ solution that contained $0.1 \mathrm{wt} \%$ of $\mathrm{AQ}$, with a liquid-to-solid ratio of $5: 1$. The remaining pulp was washed and purified. The bagasse pulp was then subjected to a threestep bleaching process. In the first stage $\left(\mathrm{D}_{0}\right), \mathrm{ClO}_{2}$ was used with a $10 \%$ w/w pulp suspension at $60{ }^{\circ} \mathrm{C}$ during 30 min until the system achieved a $\mathrm{pH}$ between 2 and 3 . In the second stage $\left(\mathrm{D}_{1}\right)$, an alkaline extraction was carried out with a $5 \mathrm{wt} \% \mathrm{NaOH} 1 \mathrm{~N}$, with a $10 \% \mathrm{w} / \mathrm{w}$ pulp suspension at $70{ }^{\circ} \mathrm{C}$ for $60 \mathrm{~min}$ and final $\mathrm{pH}$ that was greater than 10.5 . In the third step $\left(\mathrm{D}_{\mathrm{L}}\right), \mathrm{ClO}_{2}$ was added in the $10 \mathrm{wt} \%$ pulp suspension with $1 \% \mathrm{ClO}_{2}$ and 0.15 wt $\% \mathrm{NaOH} 1 \mathrm{~N}$ at $80{ }^{\circ} \mathrm{C}$ for $180 \mathrm{~min}$.

Ten grams of the bleached pulp was subjected to acid hydrolysis using $200 \mathrm{~mL}$ of $64 \% \mathrm{H}_{2} \mathrm{SO}_{4}$ at $70{ }^{\circ} \mathrm{C}$ with constant agitation for $60 \mathrm{~min}$. The solution was then rapidly cooled to stop the reaction and cleaned by centrifugation at 4,000 rpm. The solution was centrifuged three times. The resultant slurry was put in a Branson MH ultrasound bath (Chicago, IL, USA) for $1 \mathrm{~h}$. The resulting material was characterized and used to prepare the acrylic hydrogels. 


\section{Atomic Force Microscopy (AFM)}

The $0.005 \mathrm{wt} \%$ NCC solutions were used in mica sample holders until the water was evaporated at room temperature. A Park System NX-10 microscope (Suwon, South Korea) was used to obtain the particle size of the NCC.

\section{Hydrogel Synthesis}

The reaction was carried out with a $20 \% \mathrm{w} / \mathrm{w}$ AA/ $80 \%$ w/w AM solution, and the MBA crosslinking agent was used in $1,2,4$, and $8 \mathrm{wt} \%$ addition levels in relation to the monomeric phase. The NCC was added in $0,0.1,0.5$, and $1.0 \mathrm{wt} \%$ addition levels in relation to the monomeric phase. The preparation of the hydrogels consisted of two steps. In the first step (16 formulations), the reactive solution was cooled to $2{ }^{\circ} \mathrm{C}$ and immediately polymerized through the addition of $1 \mathrm{~mL}$ of a DPA solution. Three grams of a photoinitiator were also added in $100 \mathrm{~mL}$ of methanol. The solution was then put in a Petri dish and exposed to ultraviolet (UV) light (FL20BLB; Lummi, Naucalpan, Mexico) for 60 min. In the second step (16 formulations), the reactive solution was kept at $2{ }^{\circ} \mathrm{C} \pm 1{ }^{\circ} \mathrm{C}$ for $24 \mathrm{~h}$ before the photopolymerization started with the addition of the photoinitiator.

Figure 1 presents the probable net formed during the polymerization reaction. Copolymerization of acrylic acid and acrylamide forms polymeric chains and MBA generates crosslinking for network formation. The authors believe it is possible that sulfate and hydroxyl groups from the NCC interacted with the hydroxyl and amine groups of the polymeric network. The hydrogels were cut into samples with dimensions of $0.5 \mathrm{~mm}^{3} \times$ $0.5 \mathrm{~mm}^{3} \times 0.3 \mathrm{~mm}^{3}$. The samples were dried until a constant weight was achieved. Doubledistilled water was added at $25{ }^{\circ} \mathrm{C}$ and held for one week to ensure that the swelling equilibrium was reached. The water was changed, and the specimens were again immersed in water during $3 \mathrm{~d}$ at $45^{\circ} \mathrm{C}$. This cycle was repeated until the final $\mathrm{pH}$ was 7 . After this cleaning process, the hydrogels were dried at room temperature for $5 \mathrm{~d}$. After drying at room temperature, the hydrogels were kept in a vacuum oven at $40{ }^{\circ} \mathrm{C}$ until they reached constant weight. The reactive solution was kept at $2{ }^{\circ} \mathrm{C} \pm 1{ }^{\circ} \mathrm{C}$ for $24 \mathrm{~h}$ before the photopolymerization started with the addition of the photoinitiator. The yield of the reaction was determined with the initial and final weight of the samples.

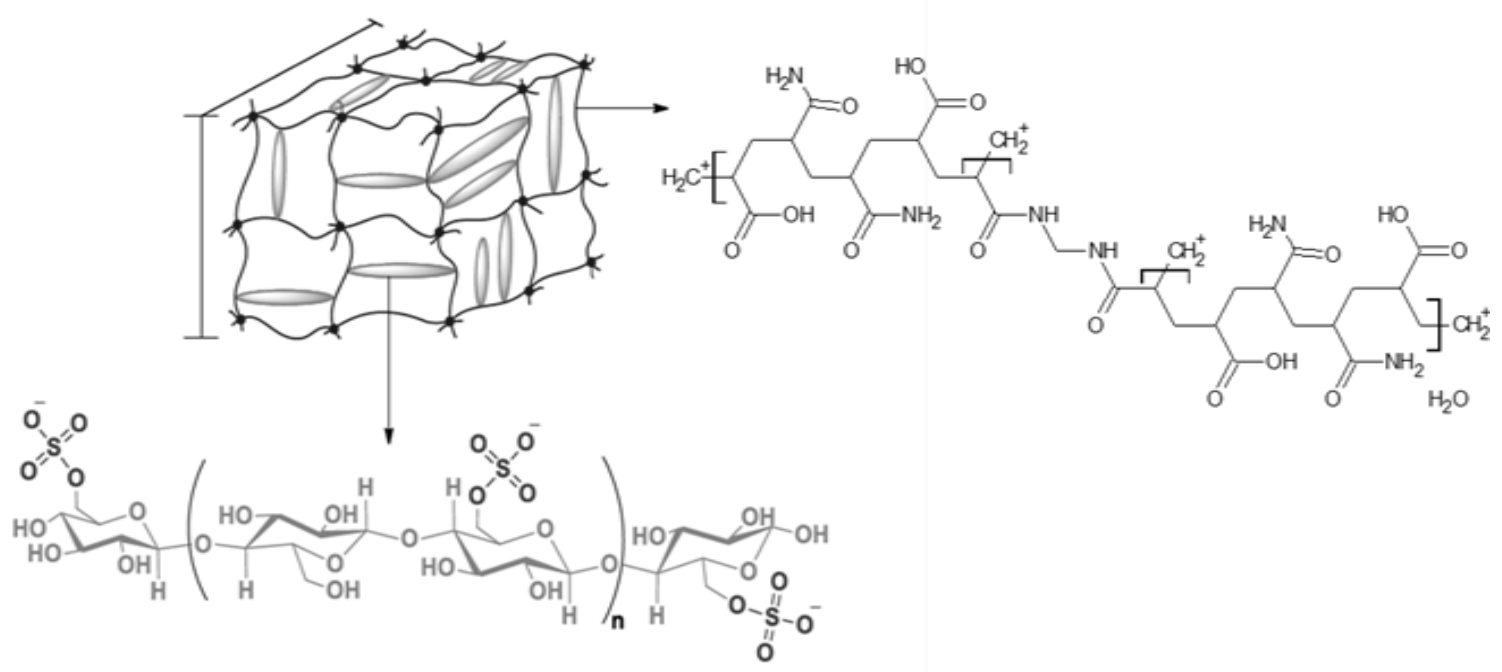

Fig. 1. Scheme of the possible net formed during the polymerization reaction 


\section{Water Absorption}

The dried samples were weighed and immersed in double-distilled water at $25{ }^{\circ} \mathrm{C}$. The samples were weighed at different periods of time. The samples were dried with absorbent paper, and the water absorption was calculated as the difference of the weights according to Eq. 1,

$$
S_{w}=\frac{W_{t}-W_{o}}{W_{o}}
$$

where $W_{t}$ is the hydrogel weight $(\mathrm{g})$ at a given time $(t)$ and $W_{o}$ is the hydrogel weight once it reached the xerogel phase.

The swelling degree was calculated according to Eq. 2 (Schott 1992),

$$
\frac{d S_{w}}{d t}=k\left(S_{W \infty}-S_{W}\right)^{2}
$$

where $S_{W \infty}$ and $S_{W}$ are the water retention values (\%) in the hydrogel swelling at equilibrium in water and at a given time $(t)$, respectively.

Equation 2 can be integrated and manipulated to obtain a linear form as follows,

$$
\frac{t}{S_{w} / S_{w \infty}}=\frac{1}{K S_{w \infty}}+t
$$

where $t$ is time and $K$ is the kinetic constant.

\section{Nuclear Magnetic Resonance (NMR)}

The nuclear magnetic resonance (NMR) analysis was carried out for the xerogels and cellulose nanocrystals in an NMR solid-state equipment model SA600 (JEOL, Tokyo, Japan) at $150 \mathrm{MHz}$ for $\mathrm{C} 13$ and with a rotation speed of $10 \mathrm{KHz}$.

\section{Scanning Electronic Microscope (SEM)}

For the morphological characterization of xerogels, an SEM TESCAN model MIRA 3LMV (Brno, Czech Republic) was used. A gold coating was applied on the samples before they were analyzed.

\section{Rheological Characterization}

The rheological properties of the hydrogels (containing 0, 0.1, 0.5, and $1.0 \mathrm{wt} \%$ of NCC) were measured in an ARG2 controlled stress rheometer from TA Instruments (New Castle, DE, USA) with geometric texturized parallel plates to avoid the sliding of the samples. The hydrogels in the swelling equilibrium were compressed at a constant speed at a temperature of $25^{\circ} \mathrm{C}$.

\section{RESULTS AND DISCUSSION}

\section{Characterization of NCC}

The cellulose contents of the A. tequilana Weber blue variety bagasse, the bleached pulp, and the NCC were $40.0 \mathrm{wt} \%, 27.6 \mathrm{wt} \%$, and $2.54 \mathrm{wt} \%$, respectively. As a sidenote, the authors believe that it may be possible to improve the isolation process of the NCC by removing the pre-hydrolysis step. Gumeta-Chavez (2009) reported yields between 17 wt\% and $50 \mathrm{wt} \%$ when Agave atrovirans pulp was used with the Acetosolv process. The acid hydrolysis treatment aims to solubilize hemicellulose and low molecular weight sugars of 
the bagasse fibers with minimal loss of cellulose (Taherzadeh and Karimi 2008). SaucedoLuna et al. (2010) reported the hydrolysis of A. tequilero using $\mathrm{H}_{2} \mathrm{SO}_{4}$ at $2 \mathrm{wt} \%$ and found cellulose, hemicellulose, and insoluble lignin contents of $42.0 \pm 1 \mathrm{wt} \%, 20.0 \pm 1 \mathrm{wt} \%$, and $15.0 \pm 1 \mathrm{wt} \%$, respectively. Sherrer and Salomón (2013) reported hemicellulose, cellulose, lignin, and soluble compound contents of $22.56 \pm 1.77 \mathrm{wt} \%, 44.19 \pm 5.66 \mathrm{wt} \%, 14.86 \pm$ $4.17 \mathrm{wt} \%$, and $18.39 \pm 5.21 \mathrm{wt} \%$, respectively. Therefore, since the cellulose yield was approximately $40 \mathrm{wt} \%$, the acid hydrolysis treatment could be used. Idarraga et al. (1999) reported cellulose yields of 40.7, 57.9, and $51.6 \mathrm{wt} \%$ for residues of A. tequilero when they were subjected to kraft, $\mathrm{NaOH}$, and ethanol- $\mathrm{NaOH}$ treatments, respectively. Santiago et al. (2002) investigated the cellulose yield of pulped sisal fibers. The sisal fibers had cellulose yields of 72 and $60.2 \mathrm{wt} \%$ at alkaline treatments of $7 \%$ and $15 \%$, respectively, at $170{ }^{\circ} \mathrm{C}$ for $15 \mathrm{~min}$.

\section{The AFM Analysis}

The atomic force microscopy (AFM) analysis revealed that the nanocellulose particles had a diameter of approximately $75 \mathrm{~nm}$, as shown in Fig. 2. The nanoparticles were short in relation to the length. This may be related to the degree of polymerization of the purified cellulose before the acid hydrolysis, which was 172.9. Agglomerates were also observed and were formed by the enhancement of interactions of the hydrogen bonds that occurred during the elimination of water (Nyström et al. 2010). Similar shapes were reported by Zhang et al. (2007), where the average size of particles was $80 \mathrm{~nm}$ with size dispersion in the range of $60 \mathrm{~nm}$ to $570 \mathrm{~nm}$ when commercial cellulose was used to synthesize the nanoparticles. Ponce-Reyes et al. (2014) reported nanocrystals with an average diameter of $97 \mathrm{~nm} \pm 30 \mathrm{~nm}$ within a range of $31 \mathrm{~nm}$ to $198 \mathrm{~nm}$. The nanocrystals were obtained from agave residues.

a)
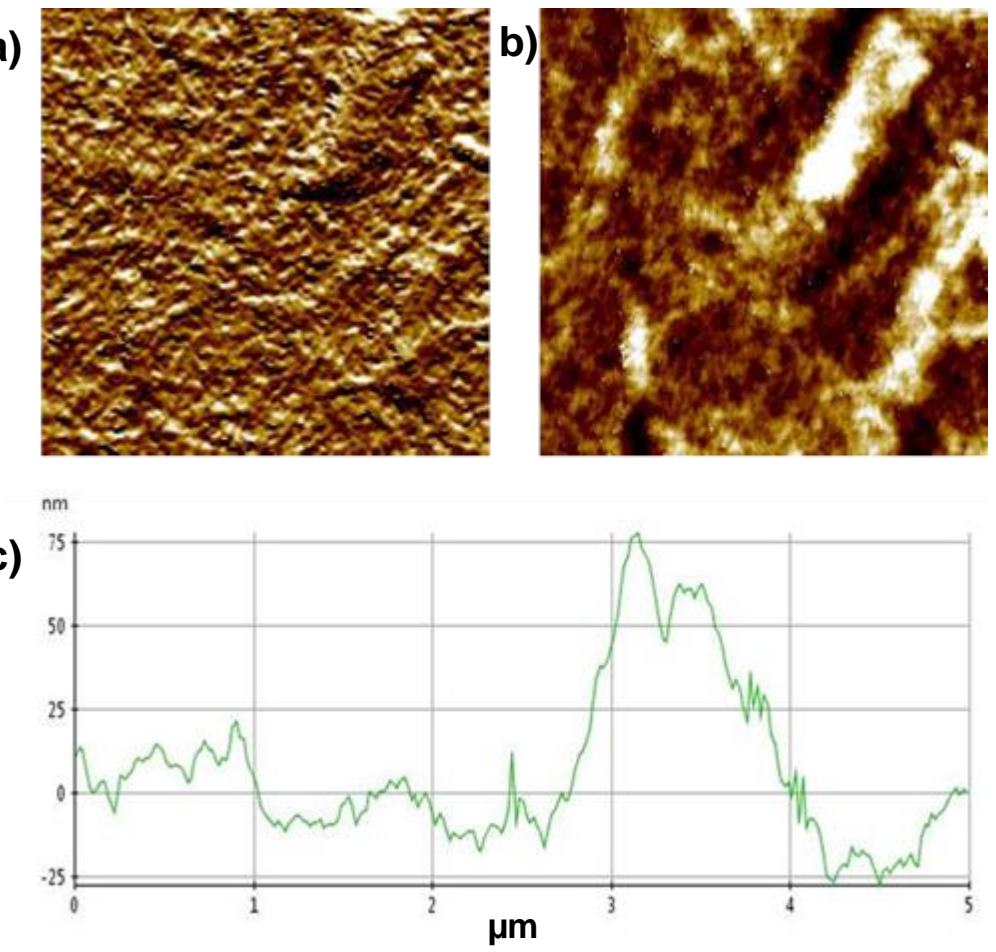

Fig. 2. AFM images of the NCC. (a, b) Micrographs of $25 \mu \mathrm{m} \times 25 \mu \mathrm{m}$ and a (c) height profile. The white regions in the AFM micrographs are the NCC particles. 


\section{The NMR Analysis}

Figure 3 shows the NMR spectra of the A. tequilana cellulose nanocrystals. The cellulose characteristic signals can be observed (Park et al. 2009; Kumar and Negi 2012). The spectra show five carbon signals. C-1 can be seen at delta $107 \mathrm{ppm}$ and $105 \mathrm{ppm}$, which corresponds to the $\beta$-D-glucopiranosa. The signals at $88.9 \mathrm{ppm}$ and $84 \mathrm{ppm}$ correspond to C-4 of the crystalline (Larsson et al. 1997; Wickholm et al. 1998) and amorphous domains, respectively. The signals at delta $75.4 \mathrm{ppm}, 74 \mathrm{ppm}$, and $72.6 \mathrm{ppm}$ correspond to C-2, C-3, and C-5, respectively, of the pyranosic ring. The last signal at delta 65 ppm is attributed to C-6 of the same structure (Ramos et al. 2005; Heinze et al. 2007; León-Fernández et al. 2013).

The crystallinity percentage in relation to C-4 was obtained by calculating the area under the curve of the crystalline and amorphous zones (Newman 1999), which resulted in a value of $66.7 \%$. Park et al. (2009) reported a crystallinity index for the dried and hydrated celluloses samples from a distinct source. For the dried cellulose, the crystallinity index ranged from $27.1 \%$ to $56.3 \%$, while the hydrated cellulose had a crystallinity index between $41.04 \%$ and $60.1 \%$.

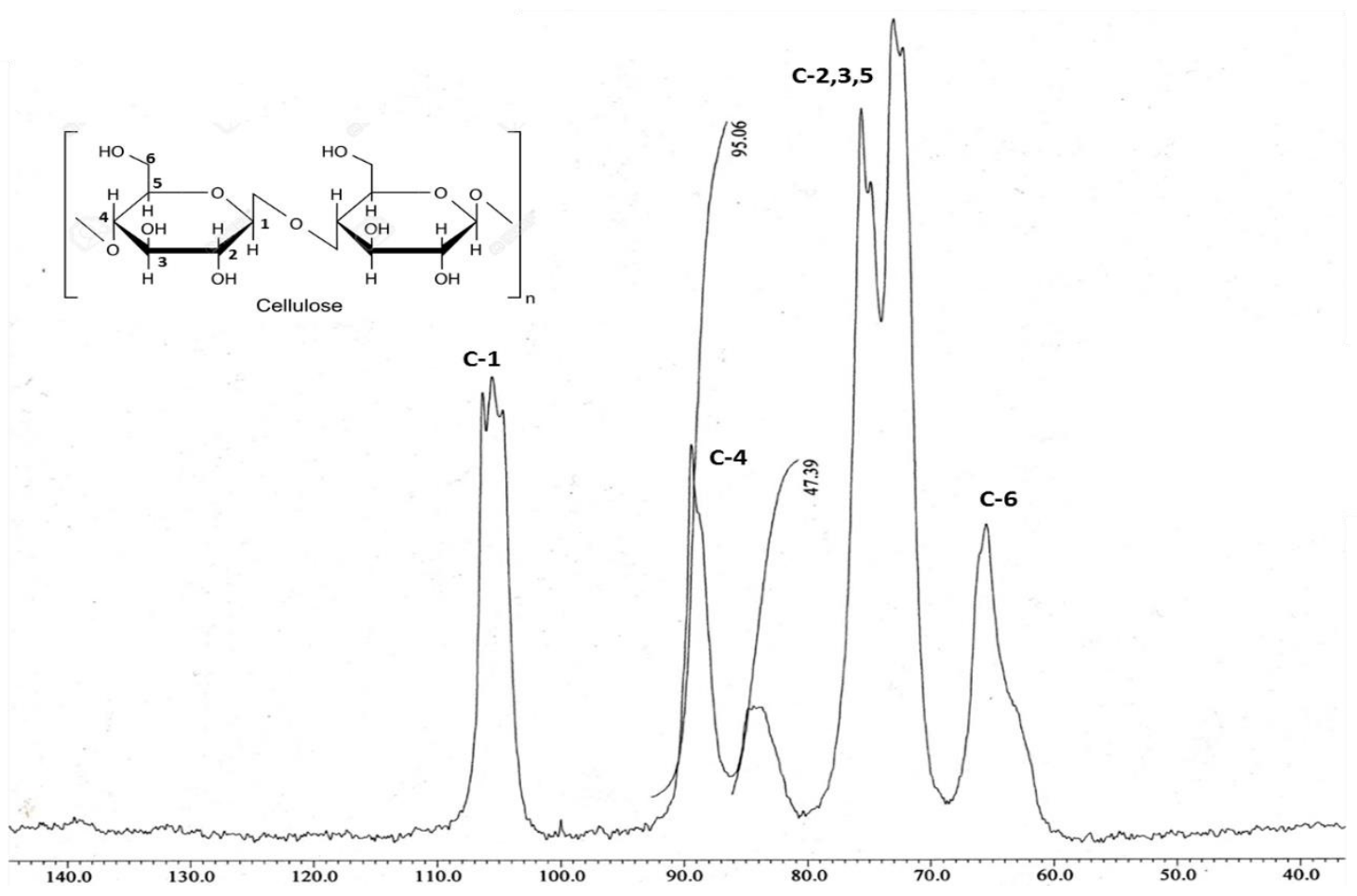

Fig. 3. NMR C13 spectrum of the A. tequilana Weber NCC

\section{Hydrogels}

Thirty-two different formulations for the hydrogels and nanohydrogels were synthesized according to the conditions and procedures mentioned in the Experimental section. The hydrogels were formed with and without thermal treatment before the reaction, and they were dosed with various concentrations of the crosslinking agent $(1,2$, 4 , and $8 \mathrm{wt} \%)$ and $\mathrm{NCC}(0,0.1,0.5$, and $1.0 \mathrm{wt} \%)$. 


\section{NMR}

Figure 4 shows the NMR C13 spectrum of the hydrogel with $1 \mathrm{wt} \%$ of NCC and $10 \mathrm{wt} \%$ of the crosslinking agent. The signals at $39.9 \mathrm{ppm}$ correspond to the carbon of the acrylic polymer chain. The signal at $180.4 \mathrm{ppm}$ correspond to the carbon attached to the amine group and to the carbon attached to the carboxylic group. Both types of carbon present signals in the same range (Mathias et al. 1990). The two peaks, parallel to the amide group, at $113.8 \mathrm{ppm}$ and $246.3 \mathrm{ppm}$ are satellite peaks that represent the spinning lateral band, which typically appears in solid state NMR. These two peaks are clearly visible since the distance of each peak to the main peak is approximately the same (Dorkoosh et al. 2000).

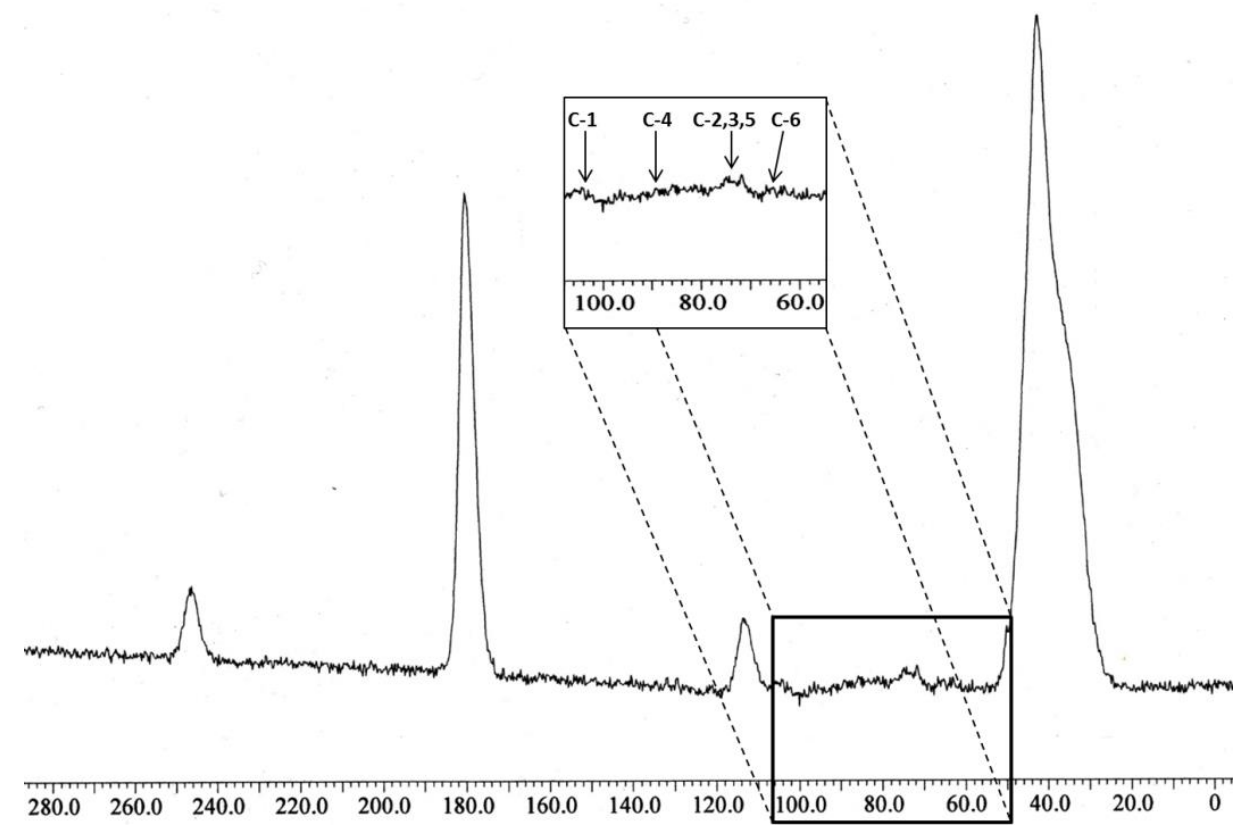

Fig. 4. NMR C13 spectrum of the A. tequilana Weber NCC hydrogels

\section{Water Absorption}

Table 1 shows the equilibrium swelling degree in water for the hydrogels and the nanohydrogels. For the hydrogels that were synthesized with the use of the thermal treatment (reactive solution was kept at $2{ }^{\circ} \mathrm{C} \pm 1{ }^{\circ} \mathrm{C}$ for $24 \mathrm{~h}$ before polymerization), the equilibrium was reached at $72 \mathrm{~h}$. For the samples synthesized without the thermal treatment (reactive solution was cooled to $2{ }^{\circ} \mathrm{C}$ and immediately polymerized), the equilibrium was reached at $58 \mathrm{~h}$. Huerta-Zapata et al. (2007) reported an equilibrium time of $50 \mathrm{~h}$ for the hydrogels with an 80/20 AA/AM content that were crosslinked with glycerol diacrylate. The swelling capacity and the swelling kinetics are affected by the type of the crosslinker, the polymerization technique, the quantity of the initiator, and the monomeric composition. López-Ureta et al. (2008) reported a swelling degree of 379 for the hydrogels with a 50/50 AA/AM ratio with glycerol diacrylate as a crosslinker. This is 370 times higher than the swelling degree that was found in the present study. Rojas et al. (2010) prepared hydrogels with a 80/20 of AM/AA ratio, using MBA as a crosslinker. Those hydrogels had a swelling degree of 25, which is three times the value found in this study.

When the crosslinking concentration was raised, the swelling degree decreased for 
both the pristine hydrogels and the nanohydrogels). The addition of the NCC did not affect the swelling degree. However, this can reduce the water absorption because of the presence of sulfate and hydroxyl groups. These groups can interact within the polymeric network to generate secondary interactions and cause greater crosslinking.

When the materials with and without the thermal treatment were compared, it was observed that the swelling degree was lower for the thermally treated samples (Fig. 5). Camacho (2007) reported the synthesis of hydrogels with a 50/50 AA/AM ratio. These hydrogels were crosslinked with glycerol diacrylate, with and without thermal treatment before the polymerization as a function of the treatment time. The results showed that the hydrogels with the thermal treatment presented a higher degree of structuration and lower degree of swelling than the ones without the thermal treatment. The reduction of the temperature in both systems was considered in order to have an initial (reference) temperature. By maintaining the solution at low temperatures, the entropy of the polymerization system decreased and caused a better network arrangement.

Figure 6 shows the time/swelling relationship as a function of time (Eq. 3). Linear tendencies can be observed, which indicate that the swelling kinetics follows the second order model. Table 1 displays the obtained values of the kinetic constant $K$ for all formulations. It also can be observed that $K$ rose when MBA and NCC concentrations were increased.

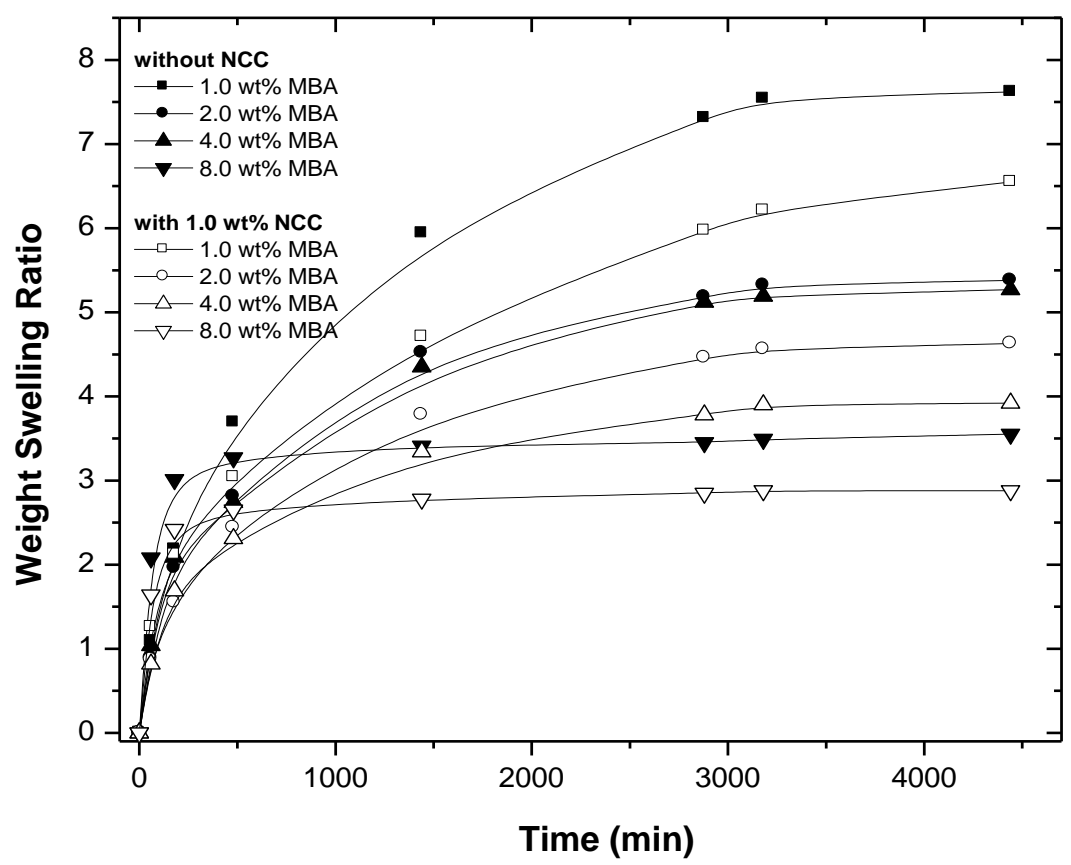

Fig. 5. Swelling degree in the equilibrium of hydrogels as a function of the NCC concentration

The dimensional stability of hydrogels in equilibrium depends on the balance between the intramolecular dispersive and cohesive forces within the hydrated chains (Jhon et al. 1976). The cohesive forces are mostly due to covalent crosslinking, electrostatic forces, and dipole-dipole interactions. In this context, NCC-reinforced hydrogels have advantages over other types of nanoparticles due to their high stability, high load capacity, biocompatibility, and sensitivity to various environmental stimuli such as temperature, $\mathrm{pH}$, ionic forces, etc. (Zhang et al. 2016). 
Table 1. Swelling Degree in the Equilibrium of the Hydrogel Formulations

\begin{tabular}{|c|c|c|c|c|c|c|c|c|}
\hline \multirow{3}{*}{$\begin{array}{c}\text { NCC } \\
\text { Content } \\
\text { (wt\%) }\end{array}$} & \multicolumn{4}{|c|}{ Swelling Degree (\%) } & \multicolumn{4}{|c|}{$\mathrm{K}\left(\mathrm{min}^{-1}\right)$} \\
\hline & \multicolumn{4}{|c|}{ MBA Content (wt\%) } & \multicolumn{4}{|c|}{ MBA Content (wt\%) } \\
\hline & 1.0 & 2.0 & 4.0 & 8.0 & 1.0 & 2.0 & 4.0 & 8.0 \\
\hline \multicolumn{9}{|c|}{ Without Thermal Treatment } \\
\hline 0.0 & $\begin{array}{c}7.62 \pm \\
0.23\end{array}$ & $\begin{array}{c}5.38 \pm \\
0.09\end{array}$ & $\begin{array}{c}5.27 \pm \\
0.10\end{array}$ & $\begin{array}{c}3.55 \pm \\
0.08\end{array}$ & 0.148 & 0.204 & 0.206 & 0.282 \\
\hline 0.1 & $\begin{array}{c}7.34 \pm \\
0.19\end{array}$ & $\begin{array}{c}5.09 \pm \\
0.07\end{array}$ & $\begin{array}{c}5.03 \pm \\
0.12\end{array}$ & $\begin{array}{c}3.43 \pm \\
0.11\end{array}$ & 0.150 & 0.212 & 0.214 & 0.291 \\
\hline 0.5 & $\begin{array}{c}6.87 \pm \\
0.18\end{array}$ & $\begin{array}{c}4.92 \pm \\
0.11\end{array}$ & $\begin{array}{c}4.45 \pm \\
0.09\end{array}$ & $\begin{array}{c}3.09 \pm \\
0.12\end{array}$ & 0.162 & 0.220 & 0.237 & 0.326 \\
\hline 1.0 & $\begin{array}{c}6.55 \pm \\
0.27\end{array}$ & $\begin{array}{c}4.63 \pm \\
0.12\end{array}$ & $\begin{array}{c}3.92 \pm \\
0.10\end{array}$ & $\begin{array}{c}2.88 \pm \\
0.09\end{array}$ & 0.166 & 0.237 & 0.274 & 0.351 \\
\hline \multicolumn{9}{|c|}{ With Thermal Treatment } \\
\hline 0 & $\begin{array}{c}7.23 \pm \\
0.10\end{array}$ & $\begin{array}{c}5.18 \pm \\
0.14\end{array}$ & $\begin{array}{c}4.95 \pm \\
0.09\end{array}$ & $\begin{array}{c}2.96 \pm \\
0.08\end{array}$ & 0.153 & 0.203 & 0.209 & 0.339 \\
\hline 0.1 & $\begin{array}{c}7.09 \pm \\
0.09\end{array}$ & $\begin{array}{c}5.12 \pm \\
0.12\end{array}$ & $\begin{array}{c}4.72 \pm \\
0.11\end{array}$ & $\begin{array}{c}2.78 \pm \\
0.13\end{array}$ & 0.157 & 0.211 & 0.228 & 0.359 \\
\hline 0.5 & $\begin{array}{c}6.95 \pm \\
0.11\end{array}$ & $\begin{array}{c}4.85 \pm \\
0.11\end{array}$ & $\begin{array}{c}4.18 \pm \\
0.08\end{array}$ & $\begin{array}{c}2.59 \pm \\
0.08\end{array}$ & 0.159 & 0.225 & 0.246 & 0.387 \\
\hline 1.0 & $\begin{array}{c}6.67 \pm \\
0.13\end{array}$ & $\begin{array}{c}4.63 \pm \\
0.11\end{array}$ & $\begin{array}{c}3.49 \pm \\
0.11\end{array}$ & $\begin{array}{c}2.38 \pm \\
0.07\end{array}$ & 0.166 & 0.236 & 0.309 & 0.421 \\
\hline
\end{tabular}

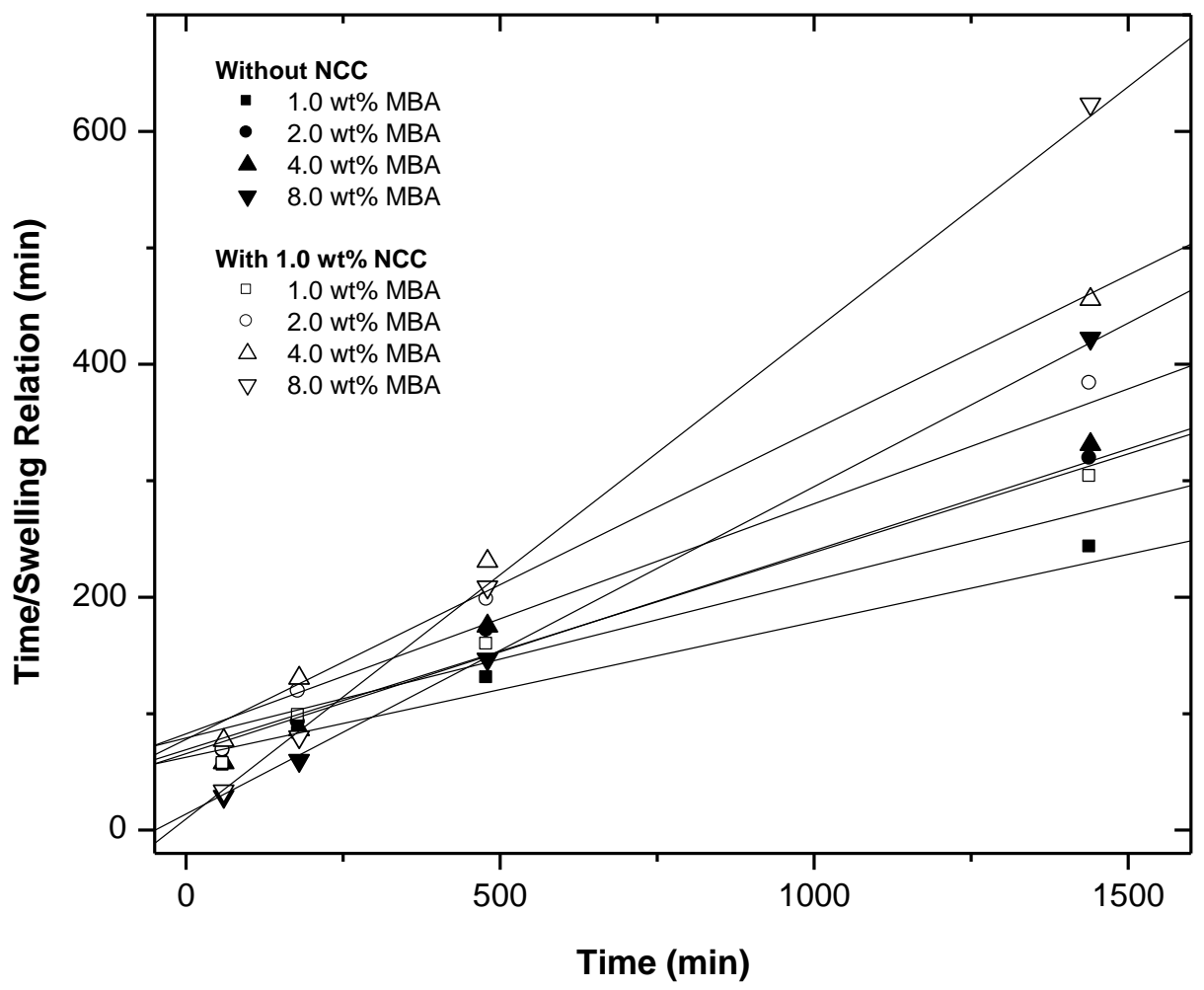

Fig. 6. Time/swelling relation as a time function, for all the hydrogel formulations 

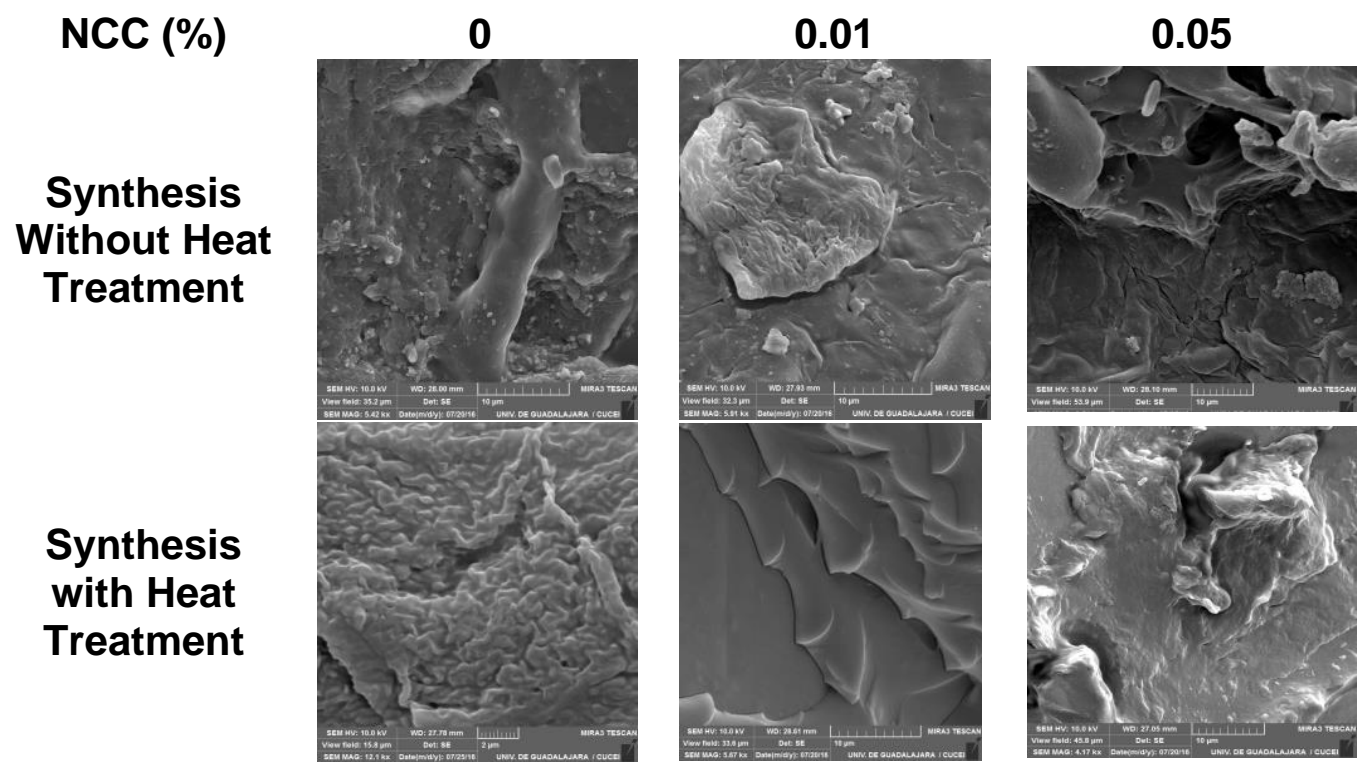

Fig. 7. SEM micrographs of the xerogels synthesized with and without the heat treatment

\section{SEM Analysis}

Figure 7 presents the SEM images of the hydrogels prepared with 1, 2, 4, and 8 $\mathrm{wt} \%$ of the crosslinking agent. All the samples that received the thermal treatment had a better morphological structuration.

\section{Rheological Properties}

Figure $8 \mathrm{a}$ shows the results obtained from the normal force/area $(F / A)$ of the hydrogels with $1 \mathrm{wt} \%$ and $2 \mathrm{wt} \%$ of crosslinking agent and $0.1 \mathrm{wt} \%$ and $0.5 \mathrm{wt} \%$ of NCC. The curves obtained were similar for all the samples that were analyzed.

a)

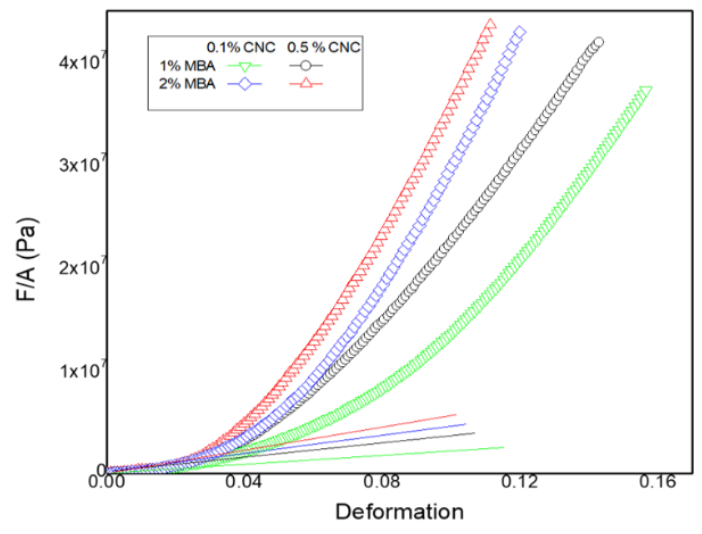

b)

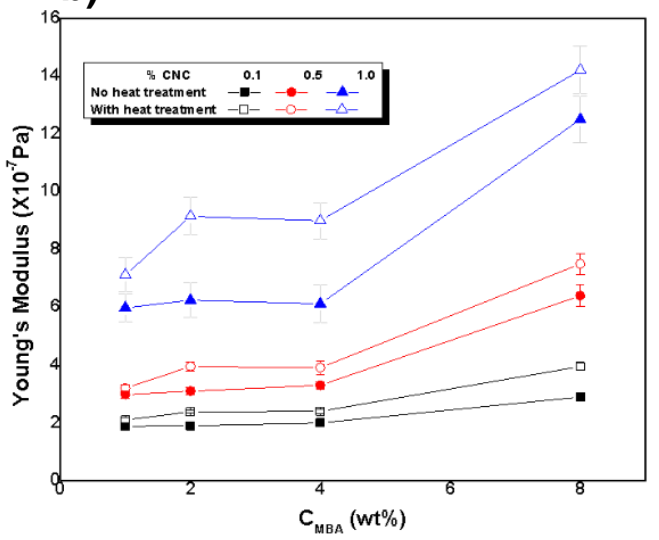

Fig. 8. a) Stress-strain curves of tensile tests performed on the swollen nanohydrogels (at the equilibrium) and the b) Young's Modulus as a function of the crosslinker of the nanohydrogels with and without the thermal treatment

The Young's modulus increased as the NCC concentration increased. Nesrinne and Dejamel (2013) synthesized hydrogels that were sensitive to $\mathrm{pH}$ with a high swelling degree and low mechanical properties, which is opposite to the results of this study. Figure 
$8 \mathrm{~b}$ shows that the Young's modulus increased as the crosslinking agent concentration increased. The highest values of the modulus were obtained when the thermal treatment was used in the synthesis of the hydrogels. The NCC concentration had the greatest benefit on the mechanical properties between the addition levels of $0.5 \mathrm{wt} \%$ and $1 \mathrm{wt} \%$. Zhou et al. (2011) synthesized AM hydrogels with NCC and found that the NCC acted as a functionalizing agent and reinforced the hydrogel net. The addition of NCC was found to lower the swelling degree and enhance the compression resistance.

\section{CONCLUSIONS}

1. Bagasse waste from A. tequilana Weber blue variety has a great potential as a raw material to produce nanocrystalline cellulose (NCC). This NCC can be used as reinforcing agent for the preparation of nanomaterials.

2. When the concentration of the crosslinker increased, the swelling degree of the treated and untreated nanohydrogels decreased.

3. The addition of NCC decreased the swelling degree.

4. Higher addition levels of the crosslinker and the NCC increased the Young`s modulus.

\section{ACKNOWLEDGMENTS}

The authors would like to acknowledge the Mexican Secretariat of Public Education for its support for the project: "Development and innovation in nanomaterials and nanocomposites, from the International Thematic Network, call 2015."

\section{REFERENCES CITED}

Brinchi, L., Cotana, F., Fortunati, E., and Kenny, J. M. (2013). "Production of nanocrystalline cellulose from lignocellulosic biomass: Technology and applications," Carbohydrate Polymers 94 (1), 154-169. DOI: 10.1016/j.carbpol.2013.01.033

Camacho C. C. (2007). Síntesis y Caracterización de un Hidrogel Acrílico MultiEstructurado. Influencia de la Historia Térmica, Master's Thesis, Universidad de Guadalajara, Mexico.

Dorkoosh, F. A., Brussee, J., Verhoef, J. C., Borchard, G., Rafiee-Tehrani, M., and Junginger, H. E. (2000). "Preparation and NMR characterization of superporous hydrogels (SPH) and SPH composites," Polymer 41(23), 8213-8220. DOI: 10.1016/S0032-3861(00)00200-7

Du, H., Liu, W., Zhang, M., Si, C., Zhang, X., and Li, B. (2019). "Cellulose nanocrystals and cellulose nanofibrils based hydrogels for biomedical applications," Carbohydrate Polymers 209, 130-144. DOI: 10.1016/j.carbpol.2019.01.020

Gallardo-Sánchez, M. A., Anzaldo-Hernández, J., Ramirez-Casillas, R., EscalanteVázquez, J. I., Escobar-Hernández, D., Soltero-Martínez, J. F. A., García-Enríquez, S., and Macias-Balleza, E. R. (2019). "Obtaining soluble-grade cellulose pulp from 
Agave tequilana Weber var. Azul Bagasse," BioResources 14, 9867-9881.

DOI:10.15376/biores.14.4.9867-9881

Gallardo-Sánchez, M. A., Diaz-Vidal, T., Navarro-Hermosillo, A. B., Figueroa-Ochoa, E. B., Ramírez-Casillas, R., Anzaldo-Hernández, J., Rosales-Rivera, L. C., SolteroMartínez, J. F. A., García-Enriquez, S., and Macías-Balleza, E. R. (2021). "Optimization of the obtaining of cellulose nanocrystals from Agave Tequilana Weber var. azul bagasse by acid hydrolysis," Nanomaterials 2021(11), 520. DOI:10.3390/nano11020520

Gómez, M. L., Williams, R. J. J., Montejano, H. A., and Previtali, C. M. (2012). "Influence of the ionic character of a drug on its release rate from hydrogels based on 2-hydroxyethylmethacrylate and acrylamide synthesized by photopolymerization," eXPRESS Polymer Letters 6(3), 189-197. DOI: 10.3144/expresspolymlett.2012.21

Gumeta-Chavez, C. (2009). Estudio del Secado Convectivo y de la Extracción de Celulosa a Través del Proceso Organosolv a Partir de Agave Atrovirens Karw, Ph.D. Dissertation, Instituto Politécnico Nacional, Mexico City, Mexico.

Habibi, Y., Lucia, L. A., and Rojas, O. J. (2010). "Cellulose nanocrystals: Chemistry, self-assembly, and applications," Chemical Reviews 110(6), 3479-3500. DOI: $10.1021 / \mathrm{cr} 900339 \mathrm{w}$

Heinze, T., Rensing, S., and Koschella, A. (2007). "Starch derivatives of high degree of functionalization. 13. Novel amphiphilic starch products," Starch 59(5), 199-207. DOI: $10.1002 /$ star.200600561

Huerta-Zapata, C.R., Reyes-González, I., García-Enriquez, S. and Bautista-Rico, F. (2007). Influencia de la Composición Química de un Hydrogel Ácido Acrilico-coacrilamida sobre la Capacidad de Hidratación, Memorias de XXVIII Encuentro Nacional de la AMIDIQ. 2685-2691, Manzanillo, Colima, México.

Huitrón, C., Pérez, R., Sánchez, A., Lappe, P., and Zavaleta, L.R. (2008). "Agricultural waste from the tequila industry as substrate for the production of commercially important enzymes," J. Environ. Biol. 1, 37-41.

Idarraga, G., Ramos, J., Zuñiga, V., Sahin, T., and Young, R. A. (1999). "Pulp and paper from blue agave waste from tequila production," Journal of Agricultural and Food Chemistry 47(10), 4450-4455. DOI: 10.1021/jf990045n

Kargarzadeh, H., Ahmad, I., Abdullah, I., Dufresne, A., Zainudin, S. Y., and Sheltami, R.M. (2012). "Effects of hydrolysis conditions on the morphology, crystallinity, and thermal stability of cellulose nanocrystals extracted from kenaf bast fibers," Cellulose 19(3), 855-866. DOI: 10.1007/s 10570-012-9684-6

Klemm, D., Cranston, E. D., Fischer, D., Gama, M., Kedzior, S. A., Kralisch, D., Kramer, F., Kondo, T., Lindström, T., Nietzsche, S., Petzold-Welcke, K., and Rauchfuss, F. (2018). "Nanocellulose as a natural source for groundbreaking applications in materials science: Today's state," Materials Today 21(7), 720-748. DOI: $10.1016 /$ j.mattod.2018.02.001

Kumar, S., and Negi, Y. S. (2012). "Corn cob xylan-based nanoparticles: Ester prodrug of 5-aminosalicylic acid for possible targeted delivery of drug," Journal of Pharmaceutical Sciences and Research 4(12), 1995-2003.

Lam, E., Male, K. B., Chong, J. H., Leung A. C. W., and Luong, J. H. T. (2012). "Applications of functionalized and nanoparticle-modified nanocrystalline cellulose," Trends in Biotechnology 30(5), 283-290. DOI: 10.1016/j.tibtech.2012.02.001

Larsson, P. T., Wickholm, K., and Iversen, T. (1997). "A CP/MAS ${ }^{13}$ C NMR investigation of molecular ordering in celluloses," Carbohydrate Research 302(1-2), 
19-25. DOI: 10.1016/S0008-6215(97)00130-4

León-Fernández, V., Rieumont-Briones, J., Bordallo-López, E., Dopico-Ramírez, D., Peña-Sacerio, E., and Menéndez-Cuesta-Mirabal, I. (2013). "Obtención y caracterización de la celulosa hidrofobicamente modificada," ICIDCA. Sobre los Derivados de la Caña de Azúcar 47(1), 51-56

Morelli, C. P., Marconcini, J. M., Pereira, F. V., Bretas, R. E. S., and Branciforti, C. M. (2012). "Extraction and characterization of cellulose nanowhiskers from balsa wood," Macromolecular Symposia 319(1), 191-195. DOI: 10.1002/masy.201100158

López-Ureta, L. C., Orozco-Guareño, E., Cruz-Barba, L. E., Gonzalez-Alvarez, A., and Bautista-Rico, F. (2008). "Synthesis and characterization of acrylamide/acrylic acid hydrogels crosslinked using a novel diacrylate of glycerol to produce multistructured materials," Journal of Polymer Science Part A: Polymer Chemistry 46(8), 2667-2679. DOI: $10.1002 /$ pola.22598

Masruchin, N., Park, B.-D., Causin, V., and Um, I. C. (2015). "Characteristics of TEMPO-oxidized cellulose fibril-based hydrogels induced by cationic ions and their properties," Cellulose 22(3), 1993-2010. DOI: 10.1007/s10570-015-0624-0

Mathias, L. J., Colletti, R. F., Halley, R. J., Jarrett, W. L., Johnson, C. G., Powell, D. G., and Warren, S. G. (1990). Solid-State NMR Polymer Spectra: Collected Volume I, MRG Polymer Press, Hattiesburg, MS, USA.

Motaung, T. E., and Mtibe, A. (2015). "Alkali treatment and cellulose nanowhiskers extracted from maize stalk residues," Materials Sciences and Applications 6(11), 1022-1032. DOI: 10.4236/msa.2015.611102

Nesrinne, S., and Djamel, A. (2013). "Synthesis, characterization and rheological behavior of $\mathrm{pH}$ sensitive poly(acrylamide-co-acrylic acid) hydrogels," Arabian Journal of Chemistry 10(4), 539-547. DOI: 10.1016/j.arabjc.2013.11.027

Newman, R. H. (1999). "Estimation of the lateral dimensions of cellulose crystallites using ${ }^{13}$ C NMR signal strengths," Solid State Nuclear Magnetic Resonance 15(1), 2129. DOI: 10.1016/S0926-2040(99)00043-0

Nyström, G., Mihranyan, A., Razaq, A., Lindström, T., Nyholm, L., and Strømme, M. (2010). "A nanocellulose polypyrrole composite based on microfibrillated cellulose from wood," The Journal of Physical Chemistry: B 114(12), 4178-4182. DOI: $10.1021 /$ jp911272m

Park, S., Johnson, D. K., Ishizawa, C. I., Parilla, P. A., and Davis, M. F. (2009). "Measuring the crystallinity index of cellulose by solid state ${ }^{13} \mathrm{C}$ nuclear magnetic resonance," Cellulose 16(4), 641-647. DOI: 10.1007/s10570-009-9321-1

Pech-Cohuo, S. C., Canche-Escamilla, G., Valadez-González, A., Fernández-Escamilla, V. V. A., and Uribe-Calderon, J. (2018). "Production and modification of cellulose nanocrystals from Agave tequilana Weber waste and its effect on the melt rheology of PLA”. Int. J. Polym. Sci. 2018. DOI:10.1155/2018/3567901.

Peng, B. L., Dhar, N., Liu, H. L., and Tam, K. C. (2011). "Chemistry and applications of nanocrystalline cellulose and its derivatives: A nanotechnology perspective," Canadian Journal of Chemical Engineering 89(5), 1191-1206. DOI: 10.1002/cjce. 20554

Pereira, A. L. S., do Nascimento, D. M., Filho, M. M. S., Morais, J. P. S., Vasconcelos, N. F., Feitosa, J. P. A., Brígida, A. I. S., and Rosa, M. F. (2014). "Improvement of polyvinyl alcohol properties by adding nanocrystalline cellulose isolated from banana pseudostems," Carbohydrate Polymers 112, 165-172. DOI:

10.1016/j.carbpol.2014.05.090

Jiménez-Amezcua et al. (2021). "Agave CNC hydrogel," BioResources 16(2), 2731-2746. 2744 
Ponce-Reyes, C. E., Chanona-Pérez, J. J., Garibay-Febles, V., Palacios-González, E., Karamath, J., Terrés-Rojas, E., and Calderón-Domínguez, G. (2014). "Preparation of cellulose nanoparticles from agave waste and its morphological and structural characterization," Revista Mexicana de Ingeniería Química 13(3), 897-906

Ramos, L. A., Frollini, E., Koschella, A., and Heinze, T. (2005). "Benzylation of cellulose in the solvent dimethylsulfoxide/tetrabutylammonium fluoride trihydrate," Cellulose 12(6), 607-619. DOI: 10.1007/s10570-005-9007-2

Rojas, G. B., Ramírez, M., Prin, J. L., Torres, C., Bejarano, L., Villarroel, H., Rojas, L., and Katime, I. (2010). "Hidrogeles de acrilamida/ácido acrilico y de acrilamida/poli (ácido acrilico): Estudio de su capacidad de remediación en efluentes industrials," Revista Latinoamericana de Metalurgia y Materiales 30(1), 28-39.

Rosa, M. F., Medeiros E. S., Malmonge, J. A., Gregorski, K. S., Wood, D. F., Mattoso, L. H. C., Glenn, G., Orts, W. J., and Imam, S. H. (2010). "Cellulose nanowhiskers from coconut husk fibers: Effect of preparation conditions on their thermal and morphological behavior," Carbohydrate Polymers 81(1), 83-92. DOI: 10.1016/j.carbpol.2010.01.059

Rosli, N. A., Ahmad, I., and Abdullah, I. (2013). "Isolation and characterization of cellulose nanocrystals from Agave angustifolia fibre," BioResources 8(2), 1893-1908.

Sanna, R., Fortunati, E., Alzari, V., Nuvoli, D., Terenzi, A., Casula, M. F., Kenny, J. M., and Mariani, A. (2013). "Poly( $N$-vinylcaprolactam) nanocomposites containing nanocrystalline cellulose: A green approach to thermoresponsive hydrogels," Cellulose 20(5), 2393-2402. DOI: 10.1007/s10570-013-9988-1

Santiago, D. I., Rodríguez, N. G., and Mogollón, G. (2002). "Potencial papelero de la fibra de sisal (Agave sisalana)," Revita Forestal Venezolana 46(2), 19-27.

Saucedo-Luna, J., Castro-Montoya, A. J., Rico, J. L., and Campos-García, J. (2010). "Optimization of acid hydrolysis of bagasse from Agave tequilana Weber," Revista Mexicana de Ingeniería Química 9(1), 91-97.

Schott, H. (1992). "Kinetics of swelling of polymers and their gels," Journal of Pharmaceutical Sciences 81(5), 467-470. DOI: 10.1002/jps.2600810516

Sherrer, A., and Salomón, J. (2013). Aprovechamiento de Bagazo de Agave Tequilana Weber Para La Producción de Bio-Hidrógeno, Master's Thesis, Instituto Potosino de Investigación Científica y Tecnológica, San Luis Potosí, Mexico.

Taherzadeh, M. J., and Karimi, K. (2008). "Pretreatment of lignocellulosic wastes to improve ethanol and biogas production: A review," International Journal of Molecular Sciences 9(9), 1621-1651. DOI: 10.3390/ijms9091621

Tequila Regulatory Council, Mexico (2020). (https://www.crt.org.mx/), Accessed October 22, 2020.

Vermonden, T., Censi, R., and Hennink, W. E. (2012). "Hydrogels for protein delivery," Chemical Reviews 112(5), 2853-2888. DOI: 10.1021/cr200157d

Wickholm, K., Larsson, P. T., and Iversen, T. (1998). "Assignment of non-crystalline forms in cellulose I by CP/MAS ${ }^{13} \mathrm{C}$ NMR spectroscopy," Carbohydrate Research 312(3), 123-129. DOI: 10.1016/S0008-6215(98)00236-5

Yang, J., Han, C.-R., Duan, J.-F., Ma, M.-G., Zhang, X.-M., Xu, F., Sun, R.-C., and Xie, X.-M. (2012). "Studies on the properties and formation mechanism of flexible nanocomposite hydrogels from cellulose nanocrystals and poly(acrylic acid)," Journal of Materials Chemistry 22(42), 22467-22480. DOI: 10.1039/C2JM35498E

Yang, X., Bakaic, E., Hoare, T., and Cranston, E. D. (2013). "Injectable polysaccharide hydrogels reinforced with cellulose nanocrystals: Morphology, rheology, degradation, 
and cytotoxicity," Biomacromolecules 14(12), 4447-4455. DOI: 10.1021/bm401364z

Zhang, C., Dan, Y., Peng, J., Turng, L.-S., Sabo, R., and Clemons, C. (2014). “Thermal and mechanical properties of natural rubber composites reinforced with cellulose nanocrystals from southern pine," Advances in Polymer Technology 33(S1), 21448. DOI: $10.1002 / \mathrm{adv} .21448$

Zhang, J., Elder, T. J., Pu, Y., and Ragauskas, A. J. (2007). "Facile synthesis of spherical cellulose nanoparticles," Carbohydrate Polymers 69(3), 607-611. DOI: 10.1016/j.carbpol.2007.01.019

Zhang, H., Zhai Y., Wang J., and Zhai G. (2016). "New progress and prospects: The application of nanogel in drug delivery," Mater. Sci. Eng. C Mater. Biol. Appl. 60: 560-568.

Zhou, C., Wu, Q., Yue, Y., and Zhang, Q. (2011). "Application of rod-shaped cellulose nanocrystals in polyacrylamide hydrogels," Journal of Colloid and Interface Science 353(1), 116-123. DOI: 10.1016/j.jcis.2010.09.035

Article submitted: December 17, 2020; Peer review completed: February 7, 2021; Revised version received and accepted: February 20, 2021; Published: February 24, 2021.

DOI: 10.15376/biores.16.2.2731-2746 